\title{
Cost-benefit analysis: a decision-support tool or a venue for contesting ecosystem knowledge?
}

Hockley, N.

\section{Environment and Planning C: Government and Policy}

DOI:

$10.1068 / \mathrm{c} 1384 \mathrm{j}$

Published: 13/03/2014

Peer reviewed version

Cyswllt i'r cyhoeddiad / Link to publication

Dyfyniad o'r fersiwn a gyhoeddwyd / Citation for published version (APA):

Hockley, N. (2014). Cost-benefit analysis: a decision-support tool or a venue for contesting ecosystem knowledge? Environment and Planning C: Government and Policy, 32(2), 283-300. https://doi.org/10.1068/c1384j

\section{Hawliau Cyffredinol / General rights}

Copyright and moral rights for the publications made accessible in the public portal are retained by the authors and/or other copyright owners and it is a condition of accessing publications that users recognise and abide by the legal requirements associated with these rights.

- Users may download and print one copy of any publication from the public portal for the purpose of private study or research

- You may not further distribute the material or use it for any profit-making activity or commercial gain

- You may freely distribute the URL identifying the publication in the public portal ?

Take down policy

Hockley, N. (2013). The definitive, peer-reviewed and edited version of this article is published in Environment and Planning C: Government and Policy, 32(2013),283-300, http://dx.doi.org/10.1068/c1384j

Take down policy

If you believe that this document breaches copyright please contact us providing details, and we will remove access to the work immediately and investigate your claim. 


\title{
Cost-Benefit Analysis: a decision-support tool or a venue for contesting ecosystem knowledge?
}

\begin{abstract}
Managing ecosystems for multiple benefits and stakeholders is a formidable challenge requiring diverse knowledge to be discovered, transmitted and aggregated. CostBenefit Analysis (CBA) is advocated as a theoretically-grounded decision-support tool, but in practice it frequently appears to exert little influence. To understand this puzzle, I consider ecosystem knowledge and CBA from both the demand- and supplysides. I argue that all ecosystem knowledge is contestable, which restricts the influence of technocratic tools like CBA. On the demand-side, democratic mechanisms shape decision-makers' motivations and incentives, but also provide a substitute for technocratic evidence. Supply-side factors limiting the influence of CBA include the scarcity of decision-pertinent evidence and the uncertain meaning and usefulness of CBA. Demand-side factors are resistant to change, but taking account of them I suggest some supply-side reforms, arguing that CBA is best regarded not as a tool, but as a venue where ecosystem knowledge is aggregated and contested.
\end{abstract}

Key words: cost-benefit analysis; ecosystem approach; knowledge utilisation; social values. 


\section{Introduction}

Representative democracy implies that numerous decisions that are binding on many people will be taken by a few. Well known characteristics of ecosystems, like the prevalence of externalities, have been held to require collective action, including intervention by governments at least since Pigou (1920, though see Backhouse \& Medema 2012). Management of ecosystems therefore requires social choices to be made: decisions on behalf of others. The ecosystems approach, which has been advocated by, amongst others, the Convention on Biological Diversity (CBD 2004) and the UK's Department for Environment Food and Rural Affairs (Defra 2011), requires that ecosystems be managed with regard to societal preferences and economic impacts (i.e. for the ecosystem services they provide to humans) while also taking account of impacts widely dispersed in space and time (Fish 2011). This poses a formidable challenge to (more or less) centralised decision making, in terms of the discovery, transmission and aggregation of knowledge (Jordan \& Russel, this issue) ${ }^{1}$.

Cost-Benefit Analysis is a technocratic tool of applied economic analysis, yet it can also be more broadly conceptualised as a 'venue' where diverse knowledge is aggregated and subjected to political and other influences. The basic building block of CBA is the net value of a decision to each individual, represented by the amount of

${ }^{1}$ I use 'knowledge' in the broad sense, including beliefs and predictions (whether correct or not) and value judgments, alongside scientific knowledge. 
money which would need to be paid or received by the individual for them to be indifferent to the decision: their willingness to $\mathrm{pay}^{2}$. However, all CBAs embody diverse information, beliefs and assumptions: e.g. moral judgments about the rights of future generations or expert guesses about the efficacy of proposed interventions. CBA is widely held by economists to have the potential to improve decision-making, for example by ensuring that hidden or diffuse costs and benefits are considered (Sunstein 2001). Economists also argue that, unique among decision-support tools, it is theoretically-based and avoids the use of arbitrary weights when aggregating information: Pearce (1998) calls it "the best game in town". Despite this enthusiasm for CBA among economists, we know that explicit technocratic evidence often appears to have "little effect" on decision-making (Weiss 1979). However, influence may be complex and the literature identifies multiple ways in which knowledge can be utilised (e.g. Weiss 1979, Owens 2005). These include: "tactical uses", when knowledge is used to promote certain interests; and the indirect "enlightenment" of decision-makers, which may occur with a considerable time lag. The aim of this paper is to review and explain the use and influence of CBA in the context of decisionmaking about ecosystems.

Section 2 reviews when and how CBA is used and the influence (if any) it has over decision-makers. In Section 3, I set out a conceptual framework of knowledge

2 For the purposes of this paper, I ignore the empirical and theoretical differences between willingness to pay and willingness to accept. Losers from a decision will have negative willingness to pay. Cost-Benefit Analysis is described in detail in Hanley \& Barbier 2009; Pearce et al 2006. 
discovery, transmission and aggregation in ecosystem decision-making, and use it to consider the role that CBA can play. In particular I consider the knowledge required by decision-makers, and factors influencing the demand for and supply of CBA in ecosystem decision-making. Many of the demand-side constraints on CBA's influence may be resistant to change, but in section 4 I propose some feasible reforms which might increase CBA's contribution at the margin. Section 5 concludes. 


\section{Patterns of CBA utilisation in environmental decision-making}

Much of the evidence on CBA utilisation predates widespread discussion and use of the ecosystem approach and/or relates to environmental decision-making more broadly. Nevertheless, the same challenges of integrating complex evidence are normally present, and this evidence is informative when considering decisionmaking in the context of the ecosystem approach. In this paper I use "environmental" when referring to this broader body of experience.

Since the influence of knowledge may be highly indirect it is not surprising that evidence for the effects of knowledge tends to be sparse and it is difficult to prove the absence of effect (Owens 2005, Nutley et al 2007). More subtly, even when decisions appear to follow and accord with knowledge, it is difficult to prove the direction of causality when decision-makers can influence what knowledge is discovered and how it is aggregated, as in the case of CBA. Any review of the use and influence of CBA must therefore proceed with caution. Nevertheless, drawing on models of knowledge use developed by Weiss (1979) and Owens (2005), I identify below some of the main ways in which CBA appears to have been utilised: more comprehensive reviews can be found in Pearce (1998a\&b), Hanley (2001), Turner (2007), Hahn \& Dudley (2007), Atkinson \& Mourato (2008), Hahn \& Tetlock (2008), Harrington et al (2009), and Shapiro \& Morrall (2012); see also Adelle et al (2012), Turnpenny et al, this issue.

Although all CBAs share certain foundational principles, considerable diversity is certainly possible (Sen 2001) and the practice of CBA has continually evolved in 
response to critiques from within and outwith the economics profession (Atkinson \& Mourato 2008). Different governments or departments lay down different guidelines for CBA (e.g. HM treasury 2003, Russel \& Jordan 2007) and it is therefore a venue for considerable interaction with decision-makers. CBAs as practiced tend to conform to certain conventions and are shaped as much by past practice, political forces and bureaucratic pragmatism as by economic theory.

\section{The limited use of CBA}

Outside of the US, CBA in policy appraisal has historically been rather sporadic (Turner 2007). While proponents can point to selected examples, the majority of policy decisions have been, and often still are, made without any significant CBA, and often seem to run contrary to CBA (Atkinson \& Mourato 2008). Pearce (1998a) and Hanley (2001) show how rarely CBA was used in British government in the 20th century. Pearce (1998b) makes the same point with regard to the European Union. Despite increasing guidance on environmental valuation and CBA generally (Robinson 2010) full CBA of UK government policies remains relatively rare. Major infrastructure projects may be subject to cost-benefit analyses e.g. the proposed Severn tidal barrage (HM Government 2010) but these are usually rather incomplete. Some form of project appraisal using CBA is common in certain sectors that impact upon ecosystems, such as forestry or transport, but again, these are far from comprehensive, particularly with regard to ecosystem services (Turner 2007). In the UK, Impact Assessments are routinely conducted - these aim to assess the costs to business of new regulations. However, although wider societal benefits (including 
environmental benefits) must in principle be considered, they need not be valued. In a recent review of soil protection research for Defra, colleagues and I found that valuation evidence rarely covered both costs and benefits of a policy and was often illsuited to decision-making (Robinson et al 2010). In fact, the consideration of costs and benefits is specifically prohibited in respect of several environmental policies (Pearce 1998; Russel and Jordan 2007, Russel and Turnpenny 2009). Even in the US, where $\mathrm{CBA}$ is much more entrenched than in Europe and where CBA is mandated for many environmental regulations, some areas are specifically exempt by law and many analyses are seriously deficient (Harrington et al 2009).

\section{The limited influence of CBA}

Krugman (2004) identifies a "Cassandra effect", whereby economic analyses which have considerable potential to improve the design of many policies seem to be comprehensively ignored. This certainly applies to CBA which, even when it is carried out, often has limited influence on the decision-making process. Most of the evidence on the influence of CBA comes from the US, where Hahn \& Tetlock (2008) show that the results of a CBA seem to have little effect on whether a regulation is adopted. Similarly, Shapiro \& Morrall (2012) show that political influence far outweighs that of CBA in determining whether regulations are issued.

However, the level of opposition to CBA (e.g. Ackerman \& Heinzerling 2004, see Revesz \& Livermore 2008) suggests that CBA does exert some influence, even if cases where CBA is decisive seem to be rare. Although Hahn \& Tetlock (2008) found little evidence that CBA influenced decisions on policy adoption, they did find some 
evidence that CBA exerted influence earlier in the policy process, by excluding obviously bad proposals (judged from a CBA perspective, see also Viscusi, 1995 and Morgenstern, 1997). Such 'filtering down' of CBA principles suggests that it can play an enlightenment function (Weiss 1977): encouraging those concerned with policy development to consider the costs and benefits of policies, even if they do not undertake rigorous CBA (Turner 2007). Where this work is triggered by a decision to adopt a policy, it is suggestive of Weiss' "problem solving" model (Weiss 1979). One of the most commonly cited examples of CBA influencing environmental policy in the UK is in determining the Landfill Tax (Turner et al 1998). In this case, CBA was used to set the level of the tax, even if it did not determine whether or not to adopt the policy. Similarly, economic analyses of the environment such as The Economics of Ecosystems and Biodiversity (TEEB, Ten Brink 2012) and the UK's National Ecosystem Assessment (NEA, UNEP WCMC 2011) may have achieved some conceptual influence in demonstrating that environmental action can often be anthropocentrically justified, instead of depending on appeals to the intrinsic value of nature, though Waylen \& Young (this issue) suggests that in the case of the NEA at least, even this influence may be limited. Set against this potential conceptual influence, evidence suggests that CBA is often confined to evaluating a narrow range of predetermined options, rather than systematically exploring or generating a range of possible solutions (Hahn \& Dudley 2007, Hahn \& Tetlock 2008).

\section{Strategic use of CBA}


More questionable than CBA's enlightenment function is its strategic use (Owens 2005) as a tool to advance certain interests. For example, the UK has supported efforts to require greater consideration of the costs and benefits of regulations (if not CBA per se) in the European Union, as this is seen as being helpful to the UK's broader agenda of emphasising economic roles of the EU (e.g. as a common market) in contrast to those who wish to see it playing a more interventionist role (Pearce \& Seccombe-Hett 2000). Similarly, much of the controversy surrounding CBA, particularly in the US, has focussed on its apparent usefulness to those pushing a deregulatory agenda (Bagley 2006, Revesz \& Livermore 2008) particularly with regard to environmental issues and it seems plausible that the Reagan administration introduced widespread use of CBA to help force an ideologically predetermined agenda onto government agencies (Bagley \& Revesz 2006).

However, CBA has not proven to be an unchanging constraint on decision-making and it has evolved as societal and administration priorities have changed (see e.g. the evolution of the UK Treasury's guidelines on social discount rates: HM Treasury 2003). Many new environmental interventions pass cost-benefit tests (particularly in the US), partly because greater use of environmental valuation techniques such as contingent valuation ensures that their benefits are included (Atkinson \& Mourato 2008). Indeed, pro-environment groups have also used CBA strategically: although economic valuation was only a small part of the UK's NEA (UNEP WCMC 2011), it was heavily emphasised during the launch of the NEA report, seemingly to try to justify environmental protection in general, as well as the existence and relevance of the government department which sponsored the work (DEFRA), during a period of 
tense fiscal negotiations within government ${ }^{3}$. Similarly, the same department has funded economic valuations which seem designed primarily to make the case for the general importance of the environment within government and which have been criticised as being economically flawed (Robinson et al 2010: 114). These sorts of economic analyses, which estimate total, rather than marginal, ecosystem values (e.g Costanza et al 1997) have been influential, but widely criticised by economists (Toman 1998). More generally, although ex ante CBAs are rarely compared with actual outcomes, there is evidence in some circumstances for strong analyst bias in favour of particular agendas (Baade \& Matheson 2004). Of course, the strategic use of CBA as a tool by opposing interest groups is not necessarily undesirable, but does suggest that CBA is flexible enough that it can be used to justify, post-hoc, judgments which have already been made. It is therefore questionable to what degree CBA influences decisions.

${ }^{3}$ This observation was made to the author by an economist working for Defra. See also Waylen \& Young, this issue. 


\section{Understanding ecosystem decision-making: knowledge supply and demand}

CBA is far from common, often exerts little direct influence on decision-making and, if not hijacked by interest groups, may simply reflect, rather than shape, political agendas. For those (like this author) who believe that economic analysis has much to contribute to decision-making, this is concerning and raises several important questions: Why aren't more CBAs carried out and why aren't they more influential? Looking to the future, how could CBA achieve - and deserve - greater influence? In this section I set out a conceptual framework of the discovery, transmission and aggregation of ecosystem knowledge for decision-making, and use it to analyse the potential role of CBA.

\section{The contested knowledge required for ecosystem decision-making}

In order to make a binding decision in the interests of society a well-motivated decision-maker must have knowledge of (or make assumptions about) four aspects of the decision.

Predictions of consequences. What effect will a decision have on outcomes of importance, for example, greenhouse gas emissions, species diversity or local unemployment? Ex post, these consequences might be measured objectively. But decisions require predictions. 
Future states of the world. To predict, and judge the importance of, a decision's consequences requires projections of variables which are exogenous to the decision: e.g. the damage done by a project's $\mathrm{CO}_{2}$ emissions depends on future global emissions, which depend in turn on future income and population growth.

Individual valuations. Because decisions will often have multiple consequences for an individual, we need to know how they would trade them off: the net effect on their welfare. This is represented in CBA by their willingness to pay for the decision.

Social values. Decisions implicitly trade-off contrasting consequences over multiple individuals. There is no objectively correct way to do this (Niemeyer \& Spash 2001, Turner 2007) and any decision implies certain normative beliefs about the relative importance of individual welfare, equality, and rights (e.g. to life and property). These beliefs may be termed "other regarding preferences" (e.g. Blanco et al 2011), or "social values" (e.g. Bogaert et al 2008) since they do not pertain simply to the individual's own welfare. Each individual in society, including the decision-maker, will hold these social values and, like individual values, they are likely to be diverse (Bogaert et al 2008, Mueller 2003 p324, Johansson-Stenman 2012). Since social values include preferences for the way individuals' values and rights should be aggregated, the problem of how to aggregate them becomes recursive. There is no reason to assume that decision-makers must supply these values.

Breaking down a decision in this way highlights several useful points. First, decisions involve predictions of the future and while predictions are the ultimate aim of science, complex socio-ecological systems require extrapolation beyond existing data 
using individual judgment (Grubler \& Nakicenovic 2001). Subjectivity is therefore inherent in all knowledge pertinent to a decision ${ }^{4}$. Thus even the potential contribution of science and evidence to ecosystem decisions is limited and there is no single, correct way to aggregate subjective judgments. Second, all four knowledge types will often be highly dispersed among individuals in society and thus be challenging for technocratic mechanisms to discover and transmit.

Although not unique in this regard, ecosystem decision-making is therefore often more complex and subjective than policy areas where CBA has achieved greater influence, such as medical spending (Schlander 2008). The effects of ecosystem interventions are harder to study and predict, since sample sizes are usually smaller. Environmental economics also lacks interpersonal units of value such as Quality Adjusted Life Years (QUALYs) which have been critical in permitting CBA to exert considerable (though not complete) influence over decisions made by the UK's National Institute for Clinical Excellence (Devlin \& Parkin 2004). The demand for, and influence of, CBA in the environmental field will therefore depend in part on how well it can help decision-makers deal with the challenge of contestable and dispersed knowledge.

\section{Demand-side factors}

${ }^{4}$ Some authors argue for paternalistic valuations that disregard the "objectively bad" preferences of, for example, women who prefer traditional roles (Adler \& Posner 2006; note this is distinct from preferences which turn out to be misguided, for example due to bounded rationality). Of course, these judgments are equally subjective, only the subject making them changes. 


\section{Decision-maker motivations, incentives and capacity for CBA use}

It is simplistic to assume that decisions are always made in the interests of society, or that decision-makers will necessarily seek or be influenced by evidence (Newman et al 2012; Dunlop, this issue). Self-interested decision-makers will only use information if they are incentivised to do so, for example by higher level decisionmakers, powerful interests or influential voters (e.g. swing voters in marginal constituencies). Even benevolent decision-makers will be bound by their own cognitive limits and capacity to seek evidence (Newman et al 2012) and may be constrained by others: if the public actively distrusts economic analysis or reasoning (Caplan 2001), elected decision-makers may be disinclined to use it. Thus, the motives, incentives and capacity of decision-makers to use evidence - including from CBA - matters enormously. Whether decision makers are motivated by self-interest; by benevolent concern for the welfare of their citizens; by ideology or, as seems plausible, by some mixture of the three is contentious and difficult to determine. Motivations are difficult to define and difficult to measure empirically (see e.g., Green \& Shapiro 1994, Mueller 2003). Therefore, CBA's use and influence may be limited because decision makers are not incentivised or motivated to make good decisions or because they do not understand how to use CBA (Bax et al 2009).

\section{Democracy: a substitute and complement for explicit knowledge}

Studies of knowledge utilization have focused on the fate of more or less explicit knowledge discovered transmitted and aggregated through technocratic mechanisms: predominantly formal research carried out by academics, professionals in government agencies etc. While political factors are analysed as helping to 
determine the role this knowledge plays (e.g. Owens 2005, Nutley et al 2007), democracy is not always conceptualised as generating, transmitting and aggregating knowledge itself. Yet because each of the four knowledge types identified above are subjective and will often be dispersed(e.g. Hayek 1945, Berkes et al 2000), each can be discovered, transmitted and aggregated in democracies by voting and deliberation (Dryzek \& List 2003). Although the democratic/technocratic dichotomy is useful, each mechanism influences the other, and knowledge is exchanged between them (CBA is one venue where such exchange takes place). Indeed it is difficult to imagine any significant decision in modern government made solely on the basis of democratic or technocratic knowledge, although in some cases one mechanism may be so dominant as to obscure the influence of the other.

Votes transmit information to decision-makers about voters' beliefs and preferences, combined with incentives for vote-seeking decision-makers to use it (in the absence of vote-rigging, democracy selects for vote-seeking decision-makers whether benevolent or not, Muller 2003). Although voting is limited in its capacity to convey information, it provides politicians and agencies with an incentive to discover (e.g. through opinion polling or focus groups) more explicit information about voters' beliefs and preferences 5 . Furthermore, most democratic systems are characterised

${ }^{5}$ For example, the UK's Department for Energy and Climate change carries out a tracking survey of public attitudes to energy and climate change issues. US presidential candidates spend millions of dollars per month on opinion polling during election year. 
by some level of deliberation, which adds to the capacity of the system to discover and transmit beliefs and preferences and even to influence them (Dryzek \& List 2003).

Of course, voters may be rationally ignorant (Downs 1957), swayed by irrelevant events (Healey et al 2010) or trivial characteristics of candidates (e,g, Lenz \& Lawson 2011). These imperfections pollute signal with noise. More seriously, errors may not be randomly distributed (Caplan 2001) and self-interested politicians may take advantage by providing concentrated benefits to influential groups, while spreading costs widely among rationally ignorant or biased voters (Mueller 2003). For example, subsidies and mandates for corn ethanol in the US benefit agribusinesses at the expense of most citizens (Adler 1996) and the environment (Searchinger et al 2008). In this way, the link between preferences and policies is weakened Most fundamentally, Arrow (1951) showed that it is impossible to devise a voting system to aggregate diverse voter preferences in such a way that simultaneously satisfies certain minimal conditions (see Sen 2012 for an accessible overview). While the empirical importance of this result will vary depending on the actual distribution of voter preferences (e.g. Regenwetter et al 2007), and may be ameliorated by nonvoting deliberative features of political systems (Dryzek and List 2003), it represents a serious challenge to democratic modes of decision-making.

However, while these weaknesses may reduce the performance of the democratic mechanism in informing decisions, they should provide no comfort to evidence advocates. Democracy complements evidence, as well as substituting for it. If decision-makers are less than completely benevolent, they must be incentivised to seek and use evidence, and democracy can provide these incentives. Demand for CBA 
will be highest if it helps decision makers deliver consequences demanded by citizens and/or if citizens directly incentivise its use. This will depend on how robust, useful and comprehensible CBA makes itself to decision-makers and citizens. I consider these supply-side factors next.

\section{Supply-side factors}

\section{The limited supply of technocratic evidence}

Explicit technocratic evidence, including the judgments of experts, is a vital raw material for CBA. Recently the UK's National Ecosystem Assessment argued that we already know enough about ecosystems to take the necessary action (UNEP/WCMC 2011). Yet Waylen \& Young (this issue) demonstrate that anticipated users of the NEA find little of direct aid in making decisions about ecosystem management or policies. Systematic reviews frequently find that while many studies have been conducted on a given topic, few have been suitably designed to provide robust evidence on the effects of interventions ${ }^{6}$. This is especially true for the socio-economic effects of important ecosystem management approaches, such as community forest management (Bowler et al 2012) or protected areas (Pullin et al 2013), despite the millions of dollars spent on these interventions worldwide (Ferraro et al 2012). It may be that research into the effects of interventions is not adequately incentivised: instead, academic prestige is attached to research which claims to advance theoretical understanding of

${ }^{6}$ See for example the 40 reviews published by the Centre for Environmental Evidence and the review of reviews by Cook et al (2013b). 
ecological and social systems by testing hypotheses ${ }^{7}$. In contexts where the predictive capacity of theory is strong this approach might be sufficient to inform decision-making, but in complex socio-ecological systems characterised by nonlinearity, generalisation from theory is likely to be weak. Instead, repeated evaluations of the effects of interventions across diverse contexts are needed. However, demand for evaluations of real-world policies from those responsible for implementing them appears to be weak and depends on voters incentivising politicians to explicitly measure their success (again highlighting the interdependence of democratic and technocratic mechanisms). In addition, well-known biases against the publication of "non-significant" results and a tendency for scientific publishers to over-weight novel or surprising results further compound the problem, leading Ioannides (2005) to conclude that "most published research findings are false". Ecosystem research lags decades behind medical research in terms of the robustness of evaluations (randomised controlled trials being both rare and problematic), prevalence of systematic review, and registration of trials to avoid publication bias. Large bodies of repeated environmental evaluations permitting

7 Decisions require estimates of the probability distributions of the size of the effect of a given intervention. Conventional hypothesis testing instead focuses on constraining the probability of a type I error (false positive, e.g. falsely concluding that pollution damages an ecosystem) without regard to the probability and cost of a type II error (e.g. failing to identify pollution damage when it exists). In applied contexts, the costs of Type II errors will sometimes be more important (Gibbons et al 2007). 
meta-analysis are a public good, and seem to be undersupplied despite public funding for research.

The ecosystem knowledge supplied by the research community also seems skewed towards the natural sciences ${ }^{8}$ despite social sciences being required for formal elicitation of individual and social values and playing a considerable role in the other two knowledge types identified above. This may partly explain the lack of primary economic and social data on the consequences of ecosystem policies. However, those techniques which do exist for soliciting individual values remain problematic, despite progress (Atkinson \& Mourato 2008, see also Kling et al 2012, Carson 2012, Hausman 2012). The extent to which valuation can provide a reliable guide to true and considered preferences, without changing those preferences, remains a concern, especially in ecosystem contexts. Social values remain poorly understood and despite emerging quantitative evidence are rarely incorporated explicitly into environmental decision-making (a point I return to below). Finally, researchers have tended to avoid formal projections of the state of the world, probably because of their inherently subjective (and controversial) nature (e.g. Castles and Henderson 2003a\&b,

8 For example, by way of crude comparison, the budget of the UK's natural science focussed Natural Environment Research Council (c£300m) exceeds that of the Economic and Social Research Council (c£170m) and the Arts and Humanities Research Council (c£100m) combined yet the last two spend only a fraction of their budgets on environmental issues. Of course, it may be that funding social science research is less cost-effective, in terms of reducing uncertainties, than natural science research. 
Nakicenovic et al 2003, Grubler et al 2004). Taken together, technocratic research often has limited capability to supply the evidence needed to take decisions and this constrains the supply of CBAs and their robustness when carried out.

\section{Does CBA help decision-makers aggregate contestable knowledge?}

CBA's distinctive feature is that it renders the consequences of decisions commensurable across individuals in a more or less explicit manner (Sen 2001). Any CBA will therefore require (or assume) all four knowledge types identified above. However, CBA is focussed on individual values and the other three enter CBA in various ways, some more explicit than others.

For example, individual preferences might be elicited for decisions themselves, or for certain consequences expected (by the analyst) to be caused by them. In the former case, each individual's predictions of the consequences of the decision are bundled with their valuation of those consequences. In the latter case, predictions of consequences are rarely based on systematic review of the evidence (which may be sparse and weak) and analysts may exert considerable influence ${ }^{9}$. Where insufficient evidence exists, expert judgment may be used, but only rarely are opinions sought from multiple sources in an explicit and rigorous manner.

Individual valuations of future consequences will also depend on predictions of future conditions e.g. income growth and technological change. These conditions will either

${ }^{9}$ Of 68 articles returned by a Web of Science search for "systematic review*" AND "cost-benefit analys*", all but one (on construction) were concerned with human health interventions. 
be implicit in preferences elicited, or be assumed by the analyst, and in the latter case they are rarely explicitly stated. For example, income growth, market interest rates and the risk of project failure are, by convention, bundled together by using an exponential function to reduce (discount) the value of costs and benefits in the future. There is no particular empirical justification for using a single exponential discount function in many cases (Price 1993, Wibe 2006, Hockley 2008) ${ }^{10}$, it merely simplified the analysis in an era of limited computing power.

Finally, although CBA conventionally assumes that individual valuations are selfregarding, they are in practice likely to incorporate the individual's social values. For example, an individual's willingness to pay for petrol will incorporate the positive value to that individual of petrol consumption as well as their concern for the negative effects on others: petrol prices would be higher if environmentalists did not voluntarily restrict their consumption, out of concern for others. CBA is also underpinned by rational choice assumptions, perhaps most significantly that individuals can meaningfully trade-off all possible consequences. This assumption of commensurability lies at the heart of much controversy surrounding CBA, particularly in environmental contexts, and highlights the difficulty of separating individual and social values (Beckerman \& Pasek 1997).

${ }^{10}$ I refer here simply to that part of the discount rate which represents the opportunity cost of capital, or the rate of growth in real incomes, which are (ex post) empirically measurable quantities. The discount rate may also include an inter-generational weighting, which is a social value. See Price (1993) and Portney \& Weyant (1999) for a full treatment. 
The individual valuations in CBA therefore implicitly bundle together the other three knowledge types. The lack of systematic and explicit approach to knowledge inclusion in CBA creates considerable scope for analysts to affect the results of a CBA, reducing repeatability and reliability. This has two implications: first, CBA can act as a filter of knowledge and second, the reliability (and therefore credibility) of CBA is often likely to be low.

\section{Is CBA meaningful and useful?}

Even a CBA based on a transparent, systematic and rigorous use of good quality data can only be influential if its meaning is considered clear and pertinent by decisionmakers and interest groups. The meaning of CBA is determined by the way it renders consequences commensurable across people and time. This is seen by its advocates (including economists) as its strength, something which separates it from other forms of policy appraisal, such as multi-criteria analysis, in being theoretically grounded and avoiding arbitrary weights (Pearce 1998). However, commensurability is also the biggest problem with conventional CBA and the ultimate source of most controversy (e.g. Dasgupta 2007, Nordhaus 2007, Weitzman 2007). It is therefore not possible to evaluate CBA without reference to the theory that underlies it (Just et al 2004): CBA is based on welfare economics, but represents a stylized simplification of it.

Since Robbins (1935) most economists have formally held that welfare gains and losses could not be compared across individuals and that ethics - the consideration of rights, and equity - were beyond the discipline's scope. However, this bought objectivity at the expense of influence. Adherence to these principles meant 
economists could only describe and predict the disaggregated effects of decisions; they could not sum them, or make any recommendations. Applied economists wanted their new objective science to be able to pronounce on the desirability of policies and Kaldor (1939) and Hicks (1939) simultaneously suggested a fudge. The Kaldor-Hicks, or potential compensation, criterion broadly states that if the sum of benefits exceeds the sum of costs, the project's winners could potentially compensate the losers, and still be better off - a potential Pareto improvement. Adding up costs and benefits in this way treats them as if the social value of additional money is the same, regardless of to whom or how it accrues. If interpreted as decisive, most CBAs therefore assume that the marginal utility of money does not decline with increasing wealth ${ }^{11}$ and virtually all CBAs ignore rights and equity (oft-conflated with marginal utility of money, but conceptually separate). When called upon to do so, economists justify this approach using a shifting assemblage of reasons. I summarise these arguments and their rebuttals very briefly below (Hausman \& McPherson 2006).

11 This means that a given monetary estimate of WTP equates to the same increase in individual welfare whether the individual is rich or poor. This is inconsistent with considerable empirical evidence on human behaviour (e.g. Evans 2005). Furthermore, this simplification leads to systematic bias. CBAs which do not account for declining marginal utility of money would tend to favour the transfer of goods and services away from the poor, towards the rich, since willingness to pay is a function of ability to pay (those which do account for declining marginal utility of money would tend to favour cash transfers in the opposite direction). Neither will necessarily result in an increase in social welfare. 
CBA assumes that winners compensate losers, such that all policies are win-wins and the marginal utility of money is therefore irrelevant. Complete and accurate compensation is highly unlikely unless the project explicitly incorporates a compensation component: in which case the transaction costs of such compensation should be explicitly considered.

CBA measures "economic efficiency", morals are left to decision-makers who can take other considerations into account if they wish. This is circular: what is being efficiently produced by the project if not "social welfare"? How should decision-makers weigh up its importance against other considerations? Economic efficiency is not morally neutral (Hausmann \& McPherson 2006) or necessarily separable from equity (Atkinson \& Mourato 2008).

Society has other means of correcting for inequality caused by regressive projects: taxes and benefits. Or alternatively: society has better means of addressing pre-existing inequality than environmental projects. Yet a) taxes and benefits do not accurately cancel out the effects of policies; b) taxes and benefits have deadweight costs: if taxes must be raised as a consequence of a policy, these costs should be accounted for; c) rights are still ignored: money earned is assumed morally equivalent to money transferred by government; and d) this presumes that decision-makers and/or the voting public understand the results of $\mathrm{CBA}$ and are willing to make these adjustments.

Adjusting for the declining marginal value of money would mean some 'good' policies fail cost-benefit tests. This is circular (it presumes the unadjusted cost-benefit result is 
correct) and easily solved if the costs of compensation measures were explicitly included in a CBA: if the policy's inequities could cheaply be corrected, it would and should pass a cost benefit test.

Thus CBA relies on tacit assumptions to be able to aggregate benefits, skirting over the very problem of aggregation which CBA is supposed to solve (indeed, the problem of aggregation in CBA is analogous to the problem of aggregation in democracy, established by Arrow, 1951). It is naïve to assume that gains and losses will cancel out over repeated CBAs, or that politics is necessarily better at aggregating, say, equity concerns than efficiency concerns. We know little about what decision-makers actually perceive CBA to mean (though see Bax 2009) but I argue that its meaning is unclear, and that the role it should play in decision-making is obscure. If electoral signals and CBA recommendations conflict, how should a benevolent decision-maker weigh each against the other, when both mechanisms represent a selective and implicit bundling of all four types of knowledge?

\section{Why aren't CBAs more common and more influential?}

This conceptual framework helps explain the limited use and influence of CBA. Ecosystem decision-making requires knowledge which is contestable and subjective to a greater degree than fields like medicine where CBA appears to have greater influence. On the demand-side, incompletely benevolent decision-makers may be imperfectly incentivised by democracy to make good decisions. However, to the extent that the democratic mechanism does function, it provides a rich, if implicit, substitute for technocratic evidence, by communicating the beliefs and preferences 
which are essential to decision-making. On the supply-side, technocratic knowledge, the raw material for CBA, is undersupplied, in turn limiting the supply of robust CBA. CBA in its current form does not help decision-makers deal with the challenge of diverse, contestable and subjective knowledge. Standards of evidence synthesis, and therefore reliability, are often poor, and CBA bundles multiple types of knowledge in often opaque ways. Most fundamentally, the meaning of CBA is unclear, and while economists admit that it should not be seen as decisive, little thought seems to be given to how decision-makers should weight CBA evidence against other concerns. Even if benevolent or well-incentivised decision-makers do wish to improve decisionmaking by seeking explicit evidence, and even if sufficient evidence is available for a CBA to be completed, it is unclear how such decision-makers should use CBA to improve decision-making in many challenging contexts. Taking into account these constraints, it should not be surprising that CBA has not been more frequently used, or more influential.

\section{Could CBA achieve - and deserve - greater influence?}

Assuming that welfare economic analysis has something to offer ecosystem decisionmaking, what then can be done to increase its influence? Knowledge deficit models of evidence use have been rightly questioned (Newman 2012): one cannot assume that simply providing more evidence will increase its use in decision-making, however succinct and colourful the briefing notes in which it is communicated. However, the contestable nature of ecosystem decision-making is largely inherent and the demandside factors limiting CBA use (decision-maker motivations, and the performance of 
democracy) are largely outside the control of economists and other evidence producers: indeed, they may be outside anyone's control. Does that mean matters are hopeless? Is there a way forward without simply re-inventing discredited and naive supply-side models?

My answer is two-fold. First, a realisation of the limited influence of evidence, and the reasons for this, is healthy and valuable in its own right. It might help those who wish to improve decision-making (howsoever defined) to allocate their scarce resources more appropriately, even if, dare I say it, that meant channelling less funding to environmental scientists and economists. Second, I have argued above that CBA does not really deserve great influence at present. Reforming CBA would make it more useful to those decision-makers who do wish to make better decisions, and therefore doing so might increase demand for CBA. Any such gains would be marginal, rather than revolutionary (see Cowell \& Lennon, this issue), but that does not mean they should not be made. With these caveats in mind, I suggest some ways in which a reformed CBA could become more useful in decision-making and therefore more deserving of influence.

\section{More decision-pertinent evidence and predictions}

Evidence and predictions, the raw materials of CBA, are in short supply. However, we should be wary of calls for "more research". Vast amounts of ecosystems research is published annually, but much is ill-suited to decision-making. What is needed is a reorientation of ecosystem science methods, publishing and funding. Academics in the field (along with their employers, funders and journals) need to re-examine the relative performance of novel theoretical advances, versus repeated empirical tests 
of interventions (not necessarily RCTs, Ravallion 2009), in providing predictive power when making novel decisions about real ecosystems (Peters 1991, Cook et al 2013a). Similarly, long range projections of future states, (including income, preferences and environmental conditions) would benefit from greater attention from researchers, if only to increase their diversity and transparency (and despite their fundamentally unscientific nature).

Environmental valuation methods continue to develop, but the reliability and validity of techniques for valuing ecosystem benefits remains a concern (Atknison \& Mourato 2008, Ferraro et al 2012). In particular, the implications for reliability of research designs intended to improve validity (such as deliberative and participatory methods) remains unknown (Lo \& Spash 2012). Special attention is also required to the interaction of self-regarding and other-regarding preferences the best methods to assess these values, and their quantitative importance.

\section{More rigorous and systematic review of evidence and opinion}

More and better evidence does not imply better CBA. In ecosystem science, CBA could benefit from adopting a more rigorous and systematic approach to evidence discovery and synthesis: systematic reviews should form the basis of any environmental CBA, as they increasingly do in medicine. The procedures are by now well-established for environmental policy questions (Pullin \& Stewart 2006) and could easily be integrated into environmental CBAs. Where evidence is too sparse for meaningful meta-analysis, more rigorous and repeatable approaches to soliciting 
expert opinion would help further reduce analyst bias (e.g. Rowe \& Wright 1999, Cross et al 2012).

\section{Quantification of uncertainty}

While CBAs routinely include sensitivity analyses, these tend to be focussed on one or two parameters (e.g. the discount rate) and are therefore clumsy, particularly when uncertainties may co-correlate or interact. In reality, all numbers in a CBA will have uncertainties associated with them and these would ideally be represented as probability density functions (based on data or opinion) to allow their propagation through the analysis, providing more realistic error estimates around the final number. This would help to undermine any false impression of certainty. Another desirable consequence is that CBAs would become focussed more on identifying and valuing - uncertainties: CBAs could aid prioritisation of research funding by identifying areas where improvements in certainty would lead to the greatest societal benefits in terms of improved decision making. We know little about the payoffs (in terms of improved decision-making) to investment in different types of ecosystem research.

\section{Greater explicitness}

CBAs should become much more explicit, disaggregating rather than obscuring complex phenomena. For example, CBAs bundle multiple processes (including endogenous and exogenous risk and uncertainty, income growth, marginal utility of money and the opportunity cost of capital) into a single discount rate which applies across the project (see e.g. HM Treasury 2003, Stern 2006, Tol 2005). This was a pragmatic simplification for modest projects in an era of limited computational 
power, but is obsolete and inappropriate for many ecosystem contexts. For example, if the incomes of different stakeholders (perhaps in different countries) are expected to grow at different rates, it would be better to treat the various legitimate reasons behind discounting explicitly and separately. While the effect of changing the functional form of discount rates has been well investigated (e.g. Henderson \& Bateman 1995) there has been little research into the quantitative importance of disaggregating and varying the components of discount rates across complex projects (see e.g. Weitzman 2001, Hockley 2008). As Niemayer and Spash (2001) argue, simplification is inevitable in decision-making, but simplifications must be constantly re-appraised.

\section{A plural approach to aggregation}

Given the limited salience and legitimacy of Kaldor-Hicks efficiency, CBAs should take a more heterodox approach to aggregation (Atkinson \& Mourato 2008). Instead of presenting CBA results alongside multiple other (e.g. ethical) assessments (Turner 2007) it could be useful to incorporate these into CBA. This would use the architecture of CBA to help the decision-maker and other stakeholders explore the implications of certain ethical positions, rather than presenting them with the unenviable task of trading off, for example, "efficiency" and "equity" unassisted. As a first step, it would be easy to routinely present net benefits with and without adjustments for the marginal utility of money. Positive net benefits under the latter, but not the former, should focus attention on plausible compensation mechanisms, which could be incorporated explicitly into the CBA. This could include generic (for a given country) estimates of the deadweight costs of progressive taxation and 
spending. Thus, just as CBA has been used to check for the consistency with which environmental regulations promote Kaldor-Hicks efficiency across government (Hahn \& Tetlock 2008), it could be used to check the consistency with which policies promote welfare at the cost of Kaldor-Hicks efficiency. Consistently calculating inequality metrics for alternative policies (e.g. Bourguignon et al 2003) could allow comparisons of the welfare costs, and Kaldor-Hicks costs, of increasing equality through alternative policies.

These suggestions are immediately feasible extensions to the commendably increasing attention paid to distributional concerns in government appraisal guidance (e.g. HM Treasury 2003) and could be achieved without significantly increasing the technical complexity of CBAs: indeed, by making clear the effect of these highly subjective concerns, they would help to undermine the apparently technocratic nature of CBA. However, by themselves, they do not deal with the more fundamental problems with the structure and meaning of CBA noted above, which go beyond concerns about equity or the marginal utility of income, which have received most attention from scholars. CBA, as presently practised, does not provide any welltested basis with which to incorporate multiple individual views on rights. These imply multiple aggregations and multiple answers which pose a much more fundamental challenge to CBA than empirical uncertainties. To date this topic has received very little attention from scholars (though see Zerbe et al 2006). In the meantime, it would be feasible and constructive if CBAs routinely calculated the opportunity cost of insisting on rights, so that again these could be compared across policies. 


\section{Rethinking CBA}

Taken together, would reforming CBA in this way simply make it more complicated, and perhaps more technocratic? Not necessarily. Instead, it could change CBA from a technocratic tool used by economists to produce an answer, to one which is used by multiple stakeholders to explore the question. Instead of being something which is performed by an analyst and presented as a static document, with a fixed and final answer, CBA should become more "open source" and iterative (Turner 2007), allowing users to explore, and deliberate on, the performance of multiple policy variants and the implications of normative assumptions (see Niemayer \& Spash 2001). Such interaction is becoming more common in spatial modelling of ecosystem services (e.g. Jackson et al 2013) and may well be demanded of CBA. Such reforms might weaken the impression given that CBA is decisive, but in reality this would merely make more explicit what most economists already acknowledge: that CBAs cannot be decisive. Ultimately, CBA might not only influence centralised decisionmakers, but also become a complement to the democratic process which in turn might increase demand for CBA, as it became shaped and better understood by a broader constituency. However, this opening up of CBA might meet with resistance from those who wish to retain central control over the aggregation of knowledge and we should be cautious about assuming that changes in technique will cause changes in decisions (Adelle et al 2012).

\section{Conclusions}


New scientific or technical knowledge may change opinions, but rarely changes the decision-making system. This paper provides a conceptual framework for understanding the use and influence of ecosystem CBA, in terms of the nature of knowledge required, and demand- and supply-side factors.

Decisions about ecosystems require knowledge that is often diffuse and contested and always subjective: adopting the ecosystems approach to decision-making (CBD 2004) poses significant challenges to technocratic modes of decision-making.

On the demand-side, democratic processes should not simply be analysed as affecting explicit knowledge use. Instead they are a complement for technocratic knowledge (since knowledge utilisation depends on the decision-makers' motives, cognition and incentives), and a substitute, since democracy is itself a mechanism for discovering, aggregating, and transmitting knowledge to decision-makers, one which is not obviously worse than technocratic mechanisms like CBA.

On the supply-side, even when decision-makers have incentives to take good decisions, scarce decision-relevant knowledge will often limit the use, robustness, and influence of CBA. More fundamentally, their influence is likely reduced further by their contested and opaque meaning.

Overall, the foundational principles of CBA have much to recommend them. Indeed some form of CBA has a role to play as a venue where diverse knowledge about ecosystems can be aggregated and contested by diverse stakeholders. However, to achieve this, CBA needs to be significantly remodelled taking account of the special features of ecosystem decision-making. 


\section{Acknowledgments}

I thank participants at the VNN BRIDGE workshops for stimulating discussion. Insightful comments from the editors, three anonymous reviewers and Julia P. G. Jones greatly improved the paper. This work was part-funded by the Natural Environment Research Council.

\section{References}

Ackerman F, Heinzerling L, 2004 Priceless: on knowing the price of everything and the value of nothing (The New Press, New York)

Adelle C, Jordan A, Turnpenny J, 2012, "Proceeding in parallel or drifting apart? A systematic review of policy appraisal research and practices" Environment and Planning- C 30401

Adler J H, 1996, "Rent seeking behind the green curtain" Regulation 1926

Adler M D, Posner E A, 2006 New Foundations of Cost-Benefit Analysis (Harvard University Press, Cambridge, MA.)

Arrow K, Solow R, 1993, "Report of the NOAA panel on contingent valuation" Arrow K J, 1951 Social choice and individual values (Wiley, New York) Atkinson G, Mourato S, 2008, "Environmental cost-benefit analysis" Annual review of environment and resources 33 317-344 
Backhouse R E, Medema S G, 2012, "Economists and the analysis of government failure: fallacies in the Chicago and Virginia interpretations of Cambridge welfare economics" Cambridge journal of economics 36 981-994

Bagley N, Revesz R L, 2006, "Centralized oversight of the regulatory state" Columbia Law Review 106 1260-1329

Bax C, Elvik R, Veisten K, 2009, "Knowledge Utilisation in Road Safety Policy: Barriers to the Use of Knowledge from Economic Analysis" Knowledge, Technology \& Policy 22 275-285

Beckerman W, Pasek J, 1997, "Plural values and environmental valuation" Environmental Values 6 65-86

Berkes F, Colding J, Folke C, 2000, "Rediscovery of Traditional Ecological Knowledge as Adaptive Management" Ecological Applications 10 1251-1262

Blanco M, Engelmann D, Normann H T, 2011, "A within-subject analysis of otherregarding preferences" Games and Economic Behavior 72 321-338

Bogaert S, Boone C, Declerck C, 2008, "Social value orientation and cooperation in social dilemmas: A review and conceptual model" British Journal of Social Psychology $47453-480$

Bourguignon F, Ferreira F H G, Leite P G, 2003, "Conditional cash transfers, schooling, and child labor: micro-simulating Brazil's Bolsa Escola program" The World Bank Economic Review 17 229-254 
Bowler D E, Buyung-Ali L M, Healey J R, Jones J P G, Knight T M, Pullin A S, 2012, "Does community forest management provide global environmental benefit and improve local welfare?" Frontiers in Ecology and the Environment 10 29-36

Caplan B, 2001, "Rational ignorance versus rational irrationality" Kyklos 54 3-26

Carson R T, 2012, "Contingent Valuation: A Practical Alternative When Prices Aren't Available" The Journal of Economic Perspectives 26 27-42

Castles I, Henderson D, 2003a, "Economics, emissions scenarios and the work of the IPCC" Energy and Environment 14 415-435

Castles I, Henderson D, 2003b, "The IPCC emission scenarios: an economic-statistical critique" Energy and Environment 14 159-185

CBD, 2004, "The Ecosystem Approach", (Secretariat of the Convention on Biological Diversity, Montreal)

Coase R H, 1960, "The Problem of Social Cost" Journal of Law and Economics 3 1-44

Cook C N, Mascia M B, Schwartz M W, Possingham H P, Fuller R A, 2013a, "Achieving Conservation Science that Bridges the Knowledge-Action Boundary" Conservation Biology 27 669-678

Cook C N, Possingham H P, Fuller R A, 2013b, "Contribution of systematic reviews to management decisions" Conservation Biology 27 902-915

Costanza R, dArge R, deGroot R, Farber S, Grasso M, Hannon B, Limburg K, Naeem S, Oneill R V, Paruelo J, Raskin R G, Sutton P, vandenBelt M, 1997, "The value of the world's ecosystem services and natural capital" Nature 387 253-260 
Cross P, Rigby D, Edwards-Jones G, 2012, "Eliciting expert opinion on the effectiveness and practicality of interventions in the farm and rural environment to reduce human exposure to Escherichia coli 0157" Epidemiology and infection 1 1-12

Dasgupta P, 2007, "The Stern review's economics of climate change" National Institute Economic Review 199 4-7

Defra, 2011, "The Natural Choice: securing the value of nature", Department for Environment (The Stationery Office, London)

Devlin N, Parkin D, 2004, "Does NICE have a cost-effectiveness threshold and what other factors influence its decisions? A binary choice analysis" Health economics $\mathbf{1 3}$ $437-452$

Downs A, 1957, "An economic theory of democracy", (Harper, New York)

Dryzek J S, List C, 2003, "Social choice theory and deliberative democracy: a reconciliation" British Journal of Political Science 33 1-28

Evans D J, 2005, "The elasticity of marginal utility of consumption: Estimates for 20 OECD Countries" Fiscal Studies 26 197-224

Ferraro P J, Lawlor K, Mullan K L, Pattanayak S K, 2012, "Forest Figures: Ecosystem Services Valuation and Policy Evaluation in Developing Countries" Review of Environmental Economics and Policy 6 20-44

Fish R D, 2011, "Environmental decision making and an ecosystems approach Some challenges from the perspective of social science" Progress in Physical Geography 35 $671-680$ 
Gibbons J M, Crout N M J, Healey J R, 2007, "What role should null-hypothesis significance tests have in statistical education and hypothesis falsification?" Trends in Ecology \& Evolution 22 445-446

Green D P, Shapiro I, 1994 Pathologies of rational choice theory: A critique of applications in political science (Cambridge Univ Press)

Grübler A, Nakicenovic N, 2001, "Identifying dangers in an uncertain climate" Nature 41215

Grübler A, Nakicenovic N, Alcamo J, Davis G, Fenhann J, Hare B, Mori S, Pepper B, Pitcher H, Riahi K, Rogner H-H, Rovere E L L, Sankovski A, Schlesinger M, Shukla R P, Swart R, Victor N, Jung T Y, 2004, "Emissions scenarios: a final response" Energy and Environment 15 11-24

Hahn R W, Dudley P M, 2007, "How Well Does the US Government Do Benefit-Cost Analysis?" Review of Environmental Economics and Policy 1 192-211

Hahn R W, Tetlock P C, 2008, "Has economic analysis improved regulatory decisions?" Journal of Economic Perspectives 22 67-84

Hanley N, 1992, "Are there environmental limits to cost benefit analysis?" Environmental and Resource Economics 2 33-59

Hanley N, 2001, "Cost-benefit analysis and environmental policymaking" Environment and Planning C-Government and Policy 19 103-118

Harrington W, Heinzerling L, Morgenstern R D, 2009 Reforming Regulatory Impact Analysis (Resources for the Future, Washington) 
Hausman D M, McPherson M S, 2006 Economic analysis, moral philosophy and public policy (Cambridge University Press, New York)

Hausman J, 2012, "Contingent Valuation: From Dubious to Hopeless" The Journal of Economic Perspectives 26 43-56

Hayek F A, 1945, "The use of knowledge in society" The American Economic Review $519-530$

Healy A J, Malhotra N, Mo C H, 2010, "Irrelevant events affect voters' evaluations of government performance" Proceedings of the National Academy of Sciences 107 12804-12809

Hicks J R, 1939, "The Foundations of Welfare Economics" The Economic Journal 49 $696-712$

HM Government, 2010, "Severn Tidal Power Feasibility Study: Conclusions and Summary Report", (http://www.decc.gov.uk/en/content/cms/meeting_energy/wave_tidal/severn_tidal_ power/severn_tidal_power.aspx\#)

HM Treasury, 2003 The Green Book - Appraisal and Evaluation in Central Government (HMSO, London)

Hockley N, 2008 Cost Benefit Analysis for Global Environmental Issues, School of Environment, Natural Resources and Geography, University of Wales, Bangor

Ioannidis J P A, 2005, "Why most published research findings are false" PLoS medicine 2 e124 
Jackson B, Pagella T, Sinclair F, Orellana B, Henshaw A, Reynolds B, McIntyre N, Wheater H, Eycott A, 2013, "Polyscape: a GIS mapping toolbox providing efficient and spatially explicit landscape-scale valuation of multiple ecosystem services" Landscape and Urban Planning 112 74-88

Johansson-Stenman 0, 2012, "Are most people consequentialists?" Economics Letters $115225-228$

Just R E, Hueth D L, Andrew S, 2004 The welfare economics of public policy (E. Elgar)

Kaldor N, 1939, "Welfare Propositions of Economics and Interpersonal Comparisons of Utility" The Economic Journal 49 549-552

Kling C L, Phaneuf D J, Zhao J, 2012, "From Exxon to BP: Has Some Number Become Better than No Number?" The Journal of Economic Perspectives 26 3-26

Krugman P, 2004, "Assessing the benefits of economics research: what are the problems?", in What's Economics Worth? Valuing Policy Research. Eds P G Pardey, V H Smith (The Johns Hopkins University Press, Baltimore, MD) pp 69-86

Lo A Y, Spash C L, 2012, "Deliberative monetary valuation: in search of a democratic and value plural approach to environmental policy" Journal of Economic Surveys McCubbins M D, Noll R G, Weingast B R, 1987, "Administrative procedures as instruments of political control" Journal of Law, Economics, \& Organization 243-277 Mueller D C, 2003 Public Choice III (Cambridge University Press, Cambridge, UK) 
Nakicenovic N, Grübler A, Gaffin S, Jung T T, Kram T, Morita T, Pitcher H, Riahi K, Schlesinger M, Shukla P R, Vuuren D v, Davis G, Michaelis L, Swart R, Victor N, 2003, "IPCC SRES revisited: a response" Energy and Environment 14 187-214

Newman K, Fisher C, Shaxson L, 2012, "Stimulating Demand for Research Evidence: What Role for Capacity-building?" IDS Bulletin 43 17-24

Niemeyer S, Spash C L, 2001, "Environmental valuation analysis, public deliberation, and their pragmatic syntheses: a critical appraisal" Environment and Planning C 19 $567-586$

Nordhaus W D, 2007, "A review of the Stern Review on the Economics of Climate Change" Journal of Economic Literature 45 686-702

Nutley S M, Walter I, Davies H T O, 2007 Using evidence: How research can inform public services (The Policy Press)

Owens S, 2005, "Making a difference? Some perspectives on environmental research and policy" Transactions of the Institute of British Geographers 30 287-292

Pardey P G, Smith V H, 2004 What's economics worth? Valuing policy research (Johns Hopkins University Press)

Pearce D, 1998a, "Cost-benefit analysis and environmental policy" Oxford Review of Economic Policy 14 84-100

Pearce D W, 1998b, "Environmental Appraisal and Environmental Policy in the European Union " Environmental and Resource Economics 11 489-501 
Pearce D W, 2004, "Does European Union Environmental Policy Pass a Cost-Benefit Test?" World Economics 5 115-137

Pearce D W, Seccombe-Hett T, 2000, "Economic valuation and environmental decision-making in Europe" Environmental Science \& Technology 34 1419-1425

Peters R H, 1991 A critique for ecology (Cambridge University Press)

Pigou A C, 1920 The Economics of Welfare (Macmillan, London)

Pildes R H, Anderson E S, 1990, "Slinging arrows at democracy: Social choice theory, value pluralism, and democratic politics" Colum. L. Rev. 902121

Portney P R, Weyant J P, 1999 Discounting and Intergenerational Equity (Resources for the Future, Washington, D.C.)

Price C, 1993 Time, Discounting and Value (Blackwell, Oxford)

Pullin A S, Bangpan M, Dalrymple S, Dickson K, Haddaway N R, Healey J R, Hauari H, Hockley N, Jones J P, Knight T, 2013, "Human well-being impacts of terrestrial protected areas" Environmental Evidence 219

Pullin A S, Stewart G B, 2006, "Guidelines for systematic review in conservation and environmental management" Conservation Biology 20 1647-1656

Ravallion M, 2009, "Should the randomistas rule?" Economists' voice 6 1-5

Rayner S, 2003, "Democracy in the age of assessment: reflections on the roles of expertise and democracy in public-sector decision making" Science and public policy $30163-170$ 
Regenwetter M, Kim A, Kantor A, Ho M H R, 2007, "The unexpected empirical consensus among consensus methods" Psychological science 18 629-635

Revesz R L, Livermore M A, 2008 Retaking Rationality. How Cost-Benefits Analysis Can Better Protect the Environment and Our Health (Oxford University Press, New York)

Rich R F, 1997, "Measuring knowledge utilization: processes and outcomes" Knowledge, Technology \& Policy 10 11-24

Robbins L, 1935 An essay on the nature and significance of economic science (MacMillan, London)

Robinson D A, Cooper D, Emmett B A, Evans C D, Keith A, Lebron I, Lofts S, Norton L, Reynolds B, Tipping E, Rawlins B G, Tye A M, Watts C W, Whalley W R, Black H I J, Warren G P, Robinson S, Michaelides K, N.J. H, 2010, "Defra soil protection research in the context of the soil natural capital / ecosystem services framework. In, Project SP1607: Synthesis of Soil Protection work 1990-2008.", (Centre for Ecology and Hydrology, UK)

Rowe G, Wright G, 1999, "The Delphi technique as a forecasting tool: issues and analysis" International Journal of Forecasting 15 353-375

Russel D, Jordan A, 2007, "Gearing-up governance for sustainable development: patterns of policy appraisal in UK central government" Journal of environmental planning and management $\mathbf{5 0}$ 1-21

Russel D, Turnpenny J, 2009, "The politics of sustainable development in UK government: what role for integrated policy appraisal?" Environment and planning. $C$, Government \& policy 27340 
Schlander M, 2008, "The use of cost-effectiveness by the National Institute for Health and Clinical Excellence (NICE): no ( $\mathrm{t}$ yet an) exemplar of a deliberative process" Journal of Medical Ethics 34 534-539

Searchinger T, Heimlich R, Houghton R A, Dong F, Elobeid A, Fabiosa J, Tokgoz S, Hayes D, Yu T H, 2008, "Use of US croplands for biofuels increases greenhouse gases through emissions from land-use change" Science 319 1238-1240

Sen A, 2001, "The discipline of cost-benefit analysis", in Cost-benefit analysis Eds M D Adler, E A Posner (Chicago University Press, Chicago) pp 95-116

Sen A, 2012, "The reach of social choice theory" Social Choice and Welfare 1-14

Shapiro S, Morrall III J F, 2012, "The triumph of regulatory politics: Benefit-cost analysis and political salience" Regulation \& Governance 6 189-206

Stringham E, 2001, "Kaldor-hicks efficiency and the problem of central planning" Quarterly Journal of Austrian Economics 4 41-50

Sunstein C R, 2001, "Cognition and cost-benefit analysis", in Cost-benefit analysis: legal, economic and philosophical perspectives Eds M D Adler, E A Posner (University of Chicago Press, Chicago) pp 223-267

Sutherland W J, Freckleton R P, 2012, "Making predictive ecology more relevant to policy makers and practitioners" Philosophical Transactions of the Royal Society B: Biological Sciences 367 322-330

Sutherland W J, Pullin A S, Dolman P M, Knight T M, 2004, "The need for evidencebased conservation" Trends in Ecology \& Evolution 19 305-308 
Ten Brink P, 2012 The Economics of Ecosystems and Biodiversity in National and International Policy Making (Routledge)

Tetlock P E, 1999, "Theory-driven reasoning about plausible pasts and probable futures in world politics: are we prisoners of our preconceptions?" American Journal of Political Science 335-366

Tetlock P E, 2005 Expert political judgment: How good is it? How can we know? (Princeton University Press)

Tol R S J, 2005, "The marginal damage costs of carbon dioxide emissions: an assessment of the uncertainties" Energy Policy 33 2064-2074

Toman M, 1998, "Why not to calculate the value of the world's ecosystem services and natural capital" Ecological Economics 25 57-60

Turner R K, 2007, "Limits to CBA in UK and European environmental policy: retrospects and future prospects" Environmental \& Resource Economics 37 253-269

Turner R K, Salmons R, Powell J, Craighill A, 1998, "Green taxes, waste management and political economy" Journal of environmental management 53 121-136

Viscusi W K, 2009, "The devaluation of life" Regulation \& Governance 3 103-127

WCMC U, 2011 The UK National Ecosystem Assessment: Technical Report (UNEP WCMC, Cambridge)

Weiss C H, 1979, "The many meanings of research utilization" Public administration review 426-431 
Weitzman M L, 2007, "A review of the Stern Review on the Economics of Climate Change" Journal of Economic Literature 45 703-724

Wibe S, Carlén 0, 2006, "Is post-war economic growth exponential?" Australian Economic Review 39 147-156

Zerbe R 0, Bauman Y, Finkle A, 2006, "An aggregate measure for benefit-cost analysis" Ecological Economics $\mathbf{5 8}$ 449-461 